\title{
Brokering Community-Engaged Writing Pedagogies: Instructors Imagining and Negotiating Race, Space, and Literacy
}

\author{
Michael Blancato - Roosevelt University \\ Gavin P. Johnson - Christian Brothers University \\ Beverly J. Moss - The Ohio State University \\ Sara Wilder - University of Maryland
}

\section{KEYWORDS}

brokering; community-engaged pedagogy; literacy narratives; race; space; place

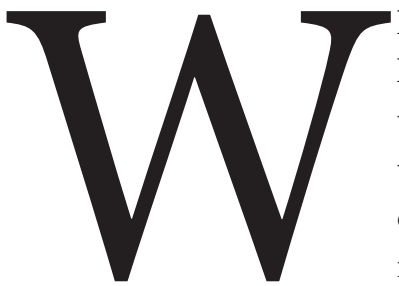

hen a community-engaged writing course centers Blackness, Black literacies, and Black spaces, instructors of these courses, especially those at predominantly white institutions (PWIs), must consider their relationships to Black community spaces and the people who occupy them. Instructor positionalities play a large role in how they facilitate this community involvement, as an instructor's embodied positionality influences their understanding of and engagement with the intersecting conditions that materially situate Black literacies across racialized spaces. Literacy studies scholarship has long considered the relationship between community-engaged writing pedagogies and positionality by often asking, how do students negotiate their identities, their racial and class subjectivities, as they work across differences? (Davi, Dunlap, and Green; Dunlap, Scoggin, Green, and Davi; Espino and Lee; Green; Kinloch, Harlem; Lum and Jacob; Shah). And while we agree that inquiry into how students in community-engaged courses negotiate positionality in community and classroom sites is vital, we suggest a focus on how instructors negotiate positionality is equally important because these negotiations inform and support community literacy pedagogies.

Even though some scholarship focuses on instructors of community-engaged writing pedagogies (Druschke, Bolinder, Pittendrigh, and Rai; Leon, Pinkert, and Taylor), such work rarely focuses explicitly on how instructors engage race in their course designs or negotiate their own identities and positionalities in their pedagogies. Given that a large number of these courses are centered in racially and ethnically minoritized community spaces, this absence is troubling. To address this scholarly gap, in this article, we consider how seven instructors of "Literacy Narratives of Black Columbus" (LNBC), a community-engaged second-year writing course at a PWI, imagined the racialized spaces and engaged racialized places of the university and surrounding communities. 
To examine the relationship among race, space, place, and identity, we deploy the concepts of community and cultural brokering, which offer a framework for understanding how instructors work with community members to forge connections between university and community spaces.

"We specifically define community brokering as the arranging of interactions between students and community members and cultural brokering as the sharing of community knowledge with students to enhance studentcommunity interactions. Community and cultural brokering enable the communityengaged writing pedagogies we study, and while we discuss community and cultural brokering as separate acts, we acknowledge that they often take place simultaneously."
Brokering, generally speaking, includes the work of imagining and facilitating interactions between university students and community members while building effective instruction and resources into a curriculum to encourage and support those interactions. We specifically define community brokering as the arranging of interactions between students and community members and cultural brokering as the sharing of

community knowledge with students to enhance student-community interactions. Community and cultural brokering enable the community-engaged writing pedagogies we study, and while we discuss community and cultural brokering as separate acts, we acknowledge that they often take place simultaneously. Although many traditionally understand brokering in the context of capitalistic relations as connecting producers of goods or services with potential clients, Steven Alvarez suggests broader social, academic, and intellectual benefits of brokering. He highlights Mexican-American children who act as language brokers between their Spanish-speaking families and English-dominant American institutions (e.g., schools, social services, etc.). While we do not share the same sociolinguistic context, we invoke Alvarez's work on brokering when focusing on the connections instructors make between students and community members for education rather than profit.

Two overarching questions guide our research on brokering:

- What kinds of interactions do instructors imagine happening between community members and students?

- How do instructors' positionalities and relationships to Blackness and Columbus's Black communities influence curricular decisions in community-engaged courses?

With these questions, we investigate the roles that instructors see themselves playing when talking with potential community participants, developing their assignments, choosing readings, and offering students feedback and support. Examining the ways instructors balance the imagined spaces of Black community literacies and the materialized places where such literacies are enacted enriches our understandings of literacy expertise, community/university relationships, difference within and beyond the classroom, and the possibility of reciprocity in community-engaged writing courses.

We argue that instructors vary in how they imagine the spaces of this course and broker the interactions between and among students and community members; we identify three approaches that illustrate diverse expressions of community and cultural brokering: 1) physically embedding 
the class, and, therefore, students in the community; 2) maintaining the place of the classroom on campus but requiring students to "go out into the community" (leave campus) to collect narratives; and 3) maintaining the traditional campus classroom space while suggesting students access the community through pre-existing networks be they on campus or not. Each approach demonstrates how instructors grapple with challenges and respond to opportunities created by the racialized and spatialized boundaries of their community-writing courses.

Below, we expand these claims and outline the three approaches to cultural and community brokering that emerged from our study. First, we briefly explain the LNBC course and the importance of space and place as concepts within the curriculum. Second, we describe our methods and introduce the instructors whose interviews inform our analysis and our understanding of cultural and community brokering. Third, we analyze instructor interviews to explain how instructor positionality influences the approaches to brokering community-engaged writing courses that emerged from our research. Based on our research, we argue that faculty and staff who teach and/ or train other instructors to teach community-engaged writing courses should consider instructor positionality and "brokering" relationships across boundaries of race, place, and space as major foci in course preparation.

\section{THE SPACES AND PLACES OF THE LITERACY NARRATIVES OF BLACK COLUMBUS}

LNBC is a service-learning designated general education (GE), second-level writing course that asks students to collect, analyze, and digitally curate literacy narratives from Black community members in Columbus, Ohio. ${ }^{1}$ LNBC students work in small groups (sometimes led by embedded graduate student "team leaders") and collect literacy narratives through qualitative audio and video interviews with Black community participants. Students then collaboratively transcribe, analyze, and curate those narratives into digital exhibits that tell stories of literacy practices in particular Black communities. The course culminates in a Community Sharing Night in which students share their exhibits with community participants and invited guests. In the course, students often travel beyond the physical places of the university campus and connect with communities that often are not their own and, perhaps, are beyond their comfort zones. By facilitating student research on the varied literacies of Columbus's Black communities-groups of people as varied as Black hair stylists, educators, dancers, veterans, poets, activists, and LGBTQIA folk, among others-the course disrupts existing understandings of literacy, and students rethink where knowledge is created and whose literacies are valued (Kinloch, Harlem; Kynard; Selfe and Ulman). In doing so, students and instructors, through careful engagement with Black communities, imagine and recognize how literacies shape and are shaped by spaces and places inflected by race.

From 2010-2013, LNBC was physically taught at Ohio State University's African and African American Community Extension Center (CEC) located in the historic Near Eastside Columbus Black community also known as the King-Lincoln District. ${ }^{2}$ A part of the Department of African and African American Studies, the CEC has existed since 1972, and it moved to its current building in the 
heart of the King-Lincoln District in 1985. As its mission, "the CEC strives to provide academic and community education opportunities for its Near Eastside neighbors and the greater Central Ohio community ... [CEC] invite[s] collaborations and dialogues focused on the diverse experiences of African Diasporic people in Columbus communities, at Ohio State, and throughout the world" ("Our Mission," emphasis in original). As Thomas Albright, Judson L. Jefferies, and N. Michael Goecke suggest, "The CEC's goal was to help uplift the Black community by providing educational and other opportunities that enhance the life chances of those who live, work, play and attend school on the near eastside" (41). Much of the programming and activities of the CEC, then, directly addresses the needs of nearby residents. Though connected to the university, the CEC is deeply embedded in the King-Lincoln District.

In 2013, the LNBC course stopped meeting at the CEC in the King-Lincoln District and moved onto Ohio State's main campus. The move from CEC was prompted in large part because some CEC administrative staff were concerned with the amount of CEC resources, especially staff time and space, that the LNBC course required. This move, initially from the CEC to main campus's Hale Hall (a building that houses the Office of Diversity and Inclusion), changed the relationship between the course and the King-Lincoln neighborhoods. The initial move created a stronger connection to the Office of Diversity and Inclusion and Hale Hall, a space where many Black students spend a great deal of time studying and "hanging out." Eventually, however, the course moved out of Hale Hall and is now regularly taught in Denney Hall, the building that houses the Department of English (a predominantly white space).

Moving the course from its initial location in the CEC to various locations on the main campus affected the ways instructors imagined students and community members' engagement in the course. Because the King-Lincoln District is no longer the focal site of LNBC, students are more likely to explore other sites in Columbus and start to understand that Black Columbus is not monolithic, that a plural conception of Black communities is more appropriate than a singular notion of the Black community. On the other hand, the visibility of the course in community spaces and among community groups surrounding CEC began to diminish. The physical location of the course on the predominantly white campus emphasizes the whiteness of Ohio State and the precarity of Black people on the campus.

We intentionally outline the spatial shifts of LNBC because we recognize the dynamic influence space and place have on learning, literacy, and positionality. We follow previous literacy studies scholars in conceptualizing "space as a social product and process" (Leander and Sheehy 1), investigating "how material settings come to be realized as social spaces" through discursive practices (Leander and Sheehy 3), and recognizing that "relocating composition teaching and learning to public sites also means critically attending to issues of space, place, and the geographies of writing" (Holmes 19). In our analysis, "space" and "place" are distinct concepts where "space" is abstract and often imagined and "place" is a realized, materialized point; however, we recognize that space and place are often overlapping. For example, we refer to LNBC instructors wanting to highlight the literacy diversity of Black community spaces through curricular planning and also encouraging student investigations of literacy practices in particular Black places like the African 
American and African Studies Community Extension Center (AAASCEC, or CEC) in Columbus's Near East Side. These distinctions, certainly, become blurred. Through our analysis, we capitalize on that blurriness when demonstrating social-cultural understandings of space; embodied experiences within places; and the ways critical literacy pedagogies address these tensions for teachers, students, and community members. We suggest the work done in the LNBC class brokers boundary crossings from imagined Black spaces to physical places of community literacy practice.

Disrupting students and instructors' "spatial practices" (Sheehy) through communityengaged writing pedagogies can generate opportunities for learning; however, the work involved in crossing intellectual and physical boundaries can often be challenging to both students and instructors (Blancato, Johnson, Moss, and Wilder). Instructors of the LNBC course served as brokers to varying degrees when facilitating meaningful community engagement. They sometimes performed the role of community broker by arranging interactions between students and

"By imagining Black spaces and engaging Black places, students can build a critical understanding of literacy in Black communities as socially and spatially situated; thus, in their pedagogical decisions, instructors imagine and facilitate spatialized and racialized practices and interactions." community members. Other times, instructors became cultural brokers, offering their own knowledge about relevant community practices. Of course, students and community participants also took on the roles of community and cultural brokers. In fact, course goals include guiding students toward learning opportunities that center the expertise and knowledge of Black community members who serve as cultural brokers for their own communities. We focus on the community and cultural brokerage of instructors to offer readers insights into how instructor identity and positionality influences their community-engaged writing pedagogies.

By imagining Black spaces and engaging Black places, students can build a critical understanding of literacy in Black communities as socially and spatially situated; thus, in their pedagogical decisions, instructors imagine and facilitate spatialized and racialized practices and interactions. This work is especially important in light of insights from Black feminist geographer Katherine McKittrick: "Space and place give black lives meaning in a world that has, for the most part, incorrectly deemed black populations and their attendant geographies 'ungeographic' and/or philosophically undeveloped" (xii). Building on McKittrick, Eric Darnell Pritchard insightfully writes that "space and place assume a more self-conscious or deliberate role in people's literacy lives" because the "construction or reconstruction of a place or space enables them to feel safer about particular literacy practices" (90). Following McKittrick and Pritchard, we understand space and place as key to understanding how Black literacies function and how they are valued for the community participants who contribute narratives to the LNBC project. 


\section{METHODS}

This article presents findings from a larger qualitative study of faculty, staff, students, and community members involved with LNBC. Here we focus on instructors' perspectives and use interviews with LNBC instructors to understand how they negotiated the racialized spaces of the course. Our data set consists of interviews with all instructors who taught LNBC at Ohio State between 2010-2018: ${ }^{3}$

- Emily, a white female English professor who co-designed LNBC;

- Thomas, a white male English associate professor who co-designed LNBC;

- Beverly, an African-American female English associate professor;

- Jason, a white male English graduate student;

- Tanya, an African-American female English graduate student;

- Michael, a white male English graduate student; and

- Gavin, a white male English graduate student.

Three of the four co-authors (Beverly, Michael, and Gavin) taught LNBC between 2013-2018.

When interviewing instructors, we organized our questions into five categories: background about the design of the course, pedagogical goals of the instructor, the role of civic engagement in the course, the role of identity in the course, and course outcomes. Additional questions were created for Emily and Thomas, the original designers of the course, about their initial vision and hopes for LNBC. After transcribing interviews, we took an iterative, inductive approach to data analysis. We individually conducted a first round of open coding for major themes. We then conducted two more rounds of coding to refine our codes. As we refined codes, not surprisingly, "Race" and "Space" emerged as two especially significant and connected categories. Our coding led us to theorize how instructors imagined racialized spaces in the course.

\section{THREE BROKERED APPROACHES TO COMMUNITY-ENGAGED WRITING PEDAGOGIES}

Using "brokering" as a conceptual framework, our data analysis yielded three general approaches to how instructors imagined and brokered connections between the classroom and community spaces in this course: embedding the course in the community, going out into the community, and relying on student networks. Each approach afforded different opportunities for cultural and community brokering by course participants_instructors, students, and community participants. As we present each approach, we engage the following key questions that emerged from our analysis:

- How do instructors understand and experience the boundary crossing from university into community spaces?

- How do instructors critically examine the ways that these spaces are racialized, along with the knowledge that is valued and the literacies that are practiced in them?

- How does the way that instructors imagine and narrate movement across boundaries stem from their own identities and positionalities? 


\section{Approach 1: Embedding the Course in the Community}

The first approach, "embedding the course in the community," relied on the initial physical placement of the LNBC course in the CEC as well as the joint efforts of the CEC with Emily and Thomas, the course co-designers and initial instructors. In particular, Emily and Thomas, both tenured white faculty, collaborated with and relied on Paulette-the CEC's senior outreach program coordinator and an African-American woman with community ties. In her interview, Emily identifies her guiding question for the course: "How do we make . . . connections outside the university that might help students also think about the importance of literacy not just within the university but throughout their lives?" Emily continues, "We started the course trying to serve the needs of . . . trying to get closer to communities and serve their needs and starting with Paulette and the AfricanAmerican and African Studies Center." Paulette sought programming that was not a one-time "in and out of the community" research project. For her, the LNBC course seemed to represent a commitment to the area and the CEC. She explains, the CEC "was connecting the community to the university resources, but also bringing the university resources and things to bear on the community and developing that kind of relationship between the two."

Thomas, who had previously worked with Paulette, relied on that connection to provide him and Emily entrance into the CEC. With Paulette's support, expertise, and community connections, Emily and Thomas set up meetings with community members months before offering the course about how the course could serve potential community participants. Paulette served as the first community broker for these early iterations of the course, providing support in the community space and providing connections to community members that Emily and Thomas, who spent little time in the CEC, did not have.

Students participating in initial course sections travelled about six miles from Ohio State's predominantly white campus to the CEC. Locating the course in the heart of a Black Columbus community-full of Black-owned businesses, social agencies, churches, and residences-laid the groundwork for a reciprocal relationship that invited community members who lived in the neighborhood to participate as "community liaisons" (Emily's term) and generated the kind of community programming Paulette sought. These community liaisons attended every class at the CEC and served as community and cultural brokers by arranging meetings between the students and other community residents and providing insights to students on their research sites. Students, therefore, didn't just read about the history and life of this neighborhood; they were immersed, at least during the class, in the Black spaces and physical places of their community participants. As community brokers, the liaisons helped students negotiate entrance into homes, churches, and other community settings for literacy interviews.

The brokering work provided by community liaisons was critically important for Emily and Thomas, who emphasized the necessity of being situated within Black communities. Thomas acknowledges the influence of physical and geographical place on the experience of his course for students: "They were in a space that celebrated African-American heritage visibly . . the displays on the walls-the community events that were advertised there." Thomas reinforced the value to students of being surrounded by Black images, people, and activities that celebrated Black life. Emily 
focuses on the value of immersion in these Black community spaces in a different way when she describes places where students collected data: “They went into people's homes. You know some of the greatest interviews were right in people's homes and just talking to them and their kids. And there's nothing more racialized, personal, I guess, than a home . . . But they also went into bars. They went into churches. They went into community centers, libraries, all of which in the context of Columbus were very racialized in that context of a culture." From Emily and Thomas's viewpoints, students understood the relationship among literacy, race, and culture filtered through the CEC, neighborhood residents, and neighborhood places. This "embedding the course in the community" provided students a necessary visible context for understanding the literacy practices of the community participants who were interviewed. More importantly, for Emily and Thomas, being embedded in the community was an important contributing factor in students learning about the complexities of Black literate lives. Their imagining of Black spaces required placement in historically Black places.

Emily and Thomas's courses, like all LNBC courses, culminated in a Community Sharing Night. Emily describes this event as a place for students to "celebrate the people with whom they had worked, and to invite everybody from the people with whom they have worked, to their friends and relatives ... and neighbors and to enjoy the time together." While sharing a meal, typically from a local Blackowned restaurant, community members saw their literacy stories recognized and commemorated. Approach 1 offers one additional benefit unique to the other approaches: locating the Community Sharing Night in the neighborhood where interviewees lived, which improved access for community participants and liaisons to attend the event.

Considering who benefited primarily in Approach 1 is a complicated task. Paulette expressed interest in seeing a course taught in the CEC that would center the community, but only after Emily and Thomas approached her with the possibility of offering a service-learning course. Paulette's support was crucial to cultivating partnerships and introducing the CEC to LNBC participants in the early iterations of the course. Paulette sought, in her words, "to get the Extension Center exposure and recognized on campus, as well as in the community, and get those two groups talking and interacting." Her interview suggests that her goals for increased recognition of the CEC and interactions between community members and the university were met.

Community participants also benefited from these early versions of the course. They requested that Thomas work with students to create hard copies of interviews that church organizations could use to preserve oral histories. In Emily's course, community participants asked to learn the process of recording and editing interviews so that they could archive oral histories themselves. Emily explains, "A lot of [the participants], especially for family purposes and for church purposes and for community purposes, were interested in learning how to use recorders, digital recorders, movie cameras, sound recordings to preserve family history, church history, a history of community groups." By joining the course as community and cultural brokers, many community participants took the opportunity to strengthen their "digital literacy" skills. The LNBC course provided the technological knowhow and resources to preserve the histories of these community groups.

Approach 1 also offered benefits to students, as they interacted with community liaisons who, 
by sharing their community and cultural knowledge, expanded students' notions of space, place, and literacy in Columbus to meet the learning objectives of the course. These learning objectives included developing written communication, analytical reading, critical thinking, and oral expression skills. By making the primary analytical content of the course interviews with community members, Emily also emphasized learning objectives that were not codified in her syllabi. Emily describes how she wanted students "to conduct a decent conversation and interview and to really dig into a particular topic and find out what they could from individuals about that topic and especially a topic where everybody has expertise and goals and practices that are interesting." In other words, Emily asked students to apply conversational and interview skills so that they could uncover the expertise and knowledge held by community participants. These goals are not unique to Emily's LNBC course. In fact, each one of the approaches we discuss in this article gives students opportunities to reconsider expertise and develop effective interview skills.

\section{Approach 2: Going Out into the Community}

Moving the course from its initial location at the CEC to classrooms on Ohio State's Columbus campus facilitated a large shift in the curricular design of the course and prompted the development of different approaches for imagining and brokering relationships between classroom and community. No longer was the course offered in a building across the street from Black-owned businesses or around the corner from a predominantly Black residential neighborhood dotted with Black churches and a Black-owned bookstore. No longer were there residential-based, community liaisons in every class session. This shift between physical locations materially impacted the ways instructors imagined Black spaces.

After the transition to Ohio State's campus, for three of the instructors-Beverly and Tanya, the two Black women instructors, and Jason, one of the four white male instructors-it was especially important for students to collect literacy narratives from Black community members outside of the university. Beverly, Jason, and Tanya instituted a "going out into the community" approach that reimagined how to emphasize the value of Black community spaces as an important lens through which to examine the literacy narratives students would collect. These instructors required students to conduct interviews in the community and invited community members and scholarly experts as guest lecturers in their classes. Beverly, Jason, and Tanya hoped having students physically in Black communities would disrupt the usual space of the classroom. Students in Beverly's classes conducted interviews in Black dance studios and Black businesses in traditionally Black neighborhoods. Students in Jason's class went to poetry readings sponsored by Black poets and held in a Black community place. Tanya offered extra credit to students who attended a Black arts festival (for which she secured complimentary passes) in the King-Lincoln District. By asking students to enter mostly unfamiliar Black places, these instructors aimed to also disrupt students' thinking about how particular literacies are valued in different spaces. The notion that art and dance, for example, are literate acts was a disruptive notion for Tanya and Beverly's students.

Beverly, a tenured associate professor, emphasizes that, in constructing the course, she wanted students to go into Black community spaces so that they developed "a respect for the knowledge 
that comes out of these community spaces and a recognition of the level of talent and the history of literacy that exists." For Beverly, going to predominantly Black spaces should prompt students to see "Black communities as rich literacy sites," to see that knowledge doesn't just come from books in the library, and to "think about [Black] people as experts and resources."

Jason, a creative writer and MFA student, focused his LNBC course on the literacies of Black poets in Columbus. He required student attendance at local poetry readings and hoped that visiting poetry readings put on by the local community of Black poets would prompt students to see and think about race and literacy differently. The Black poetry scene in Columbus offered an especially rich site in which students could see literacy practices at work. Jason acknowledges the strength and history of this community:

Specifically Columbus is a city that has had a very organized poetry community outside of the university. And a lot of the leadership in the organizing in that community over the last 20 years at least has really been done by Black people and with a specific eye, I think, towards creating spaces that are really either like ... rooms full of Black people doing poetry with other Black people and for other Black people or at least spaces that are sort of diverse and safe and comfortable for people of color.

For Jason, it was important that students go out into the community to better understand the rich history of how Black poets in Columbus created venues that celebrated and nurtured its members' literate practices. We get some insight into how students critically examined the places in which the poets compose when Jason explains, “There was a lot of explicit discussion in our interviews of processes of composition and how one conceptualizes oneself as a reader and as a writer. And specifically in terms of race, what does it mean to be a Black reader, a Black writer, what does it mean to be a person of mixed race reading and writing?" Jason imagines the students coming to a deeper understanding about how racial identity may influence one's reading and writing practices.

Tanya, a doctoral student in rhetoric, composition, and literacy, explains that her course on the literacies of Black visual artists engaged students in discussion about the expertise of visual artists beyond the university and about knowledge production in Black spaces:

What does it mean to gain expertise when many voices are not a part of that knowledge production and training? And so in the course we talked quite a bit about gentrification and zoning and how that impacts learning and the experience of Black visual artists ... basically who is being represented in certain spaces, who is not being represented in certain spaces, what that then means for their experiences and whose voices are represented ... you know this is knowledge production in the academy or universities but also this knowledge production happens in spaces beyond the walls of Ohio State. Especially among Black communities.

We see Tanya emphasizing the knowledge production her students are engaging in as members of the academy and the knowledge production in Black communities as well. In order to see knowledge production in Black communities beyond the walls of Ohio State, Tanya asked students not only to collect literacy narratives from Black artists but also to attend events featuring the work of Black visual artists in Columbus. As with Beverly and Jason, it was important to Tanya that students move 
off campus to experience a level of discomfort that might prompt them to think differently about where knowledge comes from and who makes knowledge.

The narrative of "going out into the community" reinforces the geographical and cultural separation between the University and Black Columbus, suggesting a binary and perhaps reinforcing a "suspicious" distinction between university and community spaces that Valerie Kinloch critiques. By analyzing the interplay of literacies deemed "out-of-school" and "school-sponsored," Kinloch suggests, "We can have critical conversations on why spatial conflict, contact, and difference continue to divide and separate people, places, and institutions" (159). Instructors using the "going out into the community" approach asked students to critique these distinctions between university and communities and how race complicates these spatial relationships. Tanya explains: "I think that it is important for students to confront what it means to be in a Columbus where its population or its general population is not represented in the institution that they're learning from and gaining their expertise." Each of these instructors imagined "going out into the community" as a mechanism for examining the relationship between race and literacy in Black Columbus' imagined spaces and real places. Thus, students examined texts—church sermons, poetry, hairstyling, dancing — as literate artifacts seen through the lens of race as well as gender, sexuality, and other markers of identity.

To facilitate their students' movement into Black community spaces, all three of these instructors engaged in initial brokering of interactions between community members and their students by laying the groundwork for students' community-based interviews. This brokering involved instructors meeting community members as part of course planning, assigning and discussing readings about literacy and race as well as the history of the communities, inviting community members as guest lecturers, practicing interviewing strategies, arranging for student attendance at community events, and connecting students with potential community participants among other scaffolding activities. In many ways, these instructors took on the work of the now absent community liaisons who were present in Emily's and Thomas's classes. The brokering roles that instructors took on grew, for the most part, out of their personal and professional lives coming together.

Beverly had been a long-time resident in a predominantly Black Columbus neighborhood, attends a Black church in a Black residential area, patronizes Black hair salons and other Blackowned businesses, and though not a native of Columbus was comfortable with her knowledge of many Black Columbus neighborhoods and community members. She facilitated students' entrance into these spaces through her experiences and resources. For example, for the LNBC course focused on Black dance, Beverly met with a Black dance professor at Ohio State who had not only graduated from the same Historically Black College as Beverly but who had also taught Beverly's freshman roommate at that college. This professor guest-lectured in Beverly's class and met with Beverly before the course started providing her with an overview of the Black dance community. In addition, Beverly attended church with members of one of the city's Black dance companies. It was attending this dance company's performance at a historic Black Columbus high school that sparked Beverly's interest in the relationship between Black dance and literacy. In her sections, she arranged a series of class speakers from the Black dance community and connected students with Black business owners through her personal network. Beverly, because of her situatedness within Black community spaces, 
took on the role of community broker.

In Jason's case, his personal connections to the Black poetry scene in Columbus helped provide knowledge and direction to his students. Jason, a poet, had spent a great deal of time involved in the off-campus poetry scene in Columbus, including the community of Black poets. Jason's ability to connect his academic community, through his role as teacher, with Columbus's community of Black poets, emphasizes how this course and Jason's own desire to connect across differences with a group with whom he shared a passion and skill for writing, allowed him to perform the role of community and cultural broker. In the process, he called on his experience with and knowledge of this community. Jason asked students to learn from this community by attending readings in addition to interviewing community members. Jason's identity as a poet, therefore, situated him as a community broker whose connections in poetry communities helped students gather literacy narratives. As a cultural broker, he offered students information about the work and history of Black poets in Columbus even though he did not share a racial background with the poetry community to whom he introduced his students.

Whereas Jason called on his experiences with and knowledge of the Black poetry community in Columbus, Tanya used her connections with Black visual artists to facilitate and structure student interactions with the Black visual artist community. Tanya arranged for her students to attend the Creative Central Fest (CCF) in the King-Lincoln District, and she encouraged them to speak to artists there. She also leveraged her friendship with a visual artist to set up a reciprocal partnership between this artist and her students. Specifically, the artist attended several class sessions and worked with students who composed writing projects for her gallery showing in a local museum, including her artist bio and descriptions of her individual pieces. Tanya's brokering of this partnership resulted in students not only collecting literacy narratives from Black visual artists, but also engaging in writing for a member of the community (Deans) and engaging in a reciprocal relationship with at least one visual artist. Attending the festival, talking with artists, and writing for an individual artist moved students out of their "comfort zones" and provided local contexts for community-engaged research and writing.

Beverly, Jason, and Tanya recognized the opportunities and challenges offered by students leaving campus and entering community spaces that nurtured and celebrated Black literacies. They felt it was important for students to actually see literacy in action-in the dance performances, barber shops, poetry readings, and visual art displays - in addition to interviewing community members. Each of these instructors drew on personal experiences and existing community relationships when facilitating the interactions they imagined between students and communities. As community brokers, they hoped students would recognize the rich knowledge developed and practiced in Black community spaces as well as recognize and critique the ways that their predominantly white university was itself also a racialized space: in other words, rethink the university and community spaces and the literacies attached to them through a critical lens that sees race, place, space, and literacy as inextricably bound. In many ways, all three instructors appeared to see their versions of LNBC and the students' research as offering a corrective or a revision of the literacy lives presented in popular narratives-often focusing on Black illiteracy. 
When we reflect on the benefits and challenges of Approach 2, we begin with LNBC's move from the CEC to Ohio State's main campus. The shift in physical location emphasized the obvious racial differences of the communities. These three instructors, by virtue of repeating the "going out into the community" language, positioned the university and their students as different from or in opposition to Black Columbus. Whether their students shared identities or interests with community partners (and some did), Approach 2 instructors appeared to see their students having to cross boundaries and negotiate differences in their views about knowledge production, literacy practices, and life experiences. In addition, Approach 2, while missing the immediate connections that came along with being physically situated within the King-Lincoln District, provided an opportunity for these instructors to emphasize the complexity of Black Columbus communities.

However, Approach 2, like the other approaches, required the instructors to deal with challenges. One of the major challenges with Approach 2 was engaging in reciprocal relationships between LNBC stakeholders. We see a varied, multi-tiered and sometimes complicated approach to reciprocity. Some acts of reciprocity benefitted individual community participants, some benefitted the specific community groups or sites, and others benefitted larger local communities. For example, while Tanya's students collected literacy narratives from multiple visual artists, she negotiated with one artist for whom her students would compose a bio and descriptions of her artwork for an upcoming museum exhibit. This act of reciprocity demonstrates Deans's writing for a member of the community while the other acts of reciprocity in Tanya's class centered on writing about the community. In fact, most of the projects would neatly fall into Deans's writing about category.

We see another tier of reciprocity when Jason and Tanya, by requiring their students to attend community-sponsored poetry and art events, provided new audiences for their respective community participants' work. Beverly's requirement that students collect literacy narratives in the community spaces resulted in an unexpected payoff in the Black dance community, as expressed by the executive director of one of the dance companies: "participating in the LNBC projects gave us [members of the Black dance community] an opportunity to talk to people" [outside their circle], something she suggested was much needed. While this "benefit" was identified during the Community Sharing Night, it could represent an act of reciprocity that potentially benefits Black dancers in their desire to speak to a broader community. Yet, this act was not easily identifiable as a direct benefit to the individual community participants. And we question the validity of claiming it as reciprocity. Approach 2 points to the range of opportunities for reciprocity to occur and forms that it may take. We acknowledge, however, that with the exception of Tanya's negotiation of reciprocity with one visual artist, the other acts of reciprocity in Approach 2 were not easily identifiable as directly benefiting the community participants. How did they benefit the community participants, if at all? This is always a question for community-engaged courses, especially those that resemble oral histories more than service learning.

\section{Approach 3: Accessing Communities Through Student Networks}

A third approach—accessing communities through student networks-emerged from interviews with Michael and Gavin, two white male doctoral students in rhetoric, composition, and literacy. 
Whereas Emily and Thomas's approach embedded the course in the community, and Jason, Beverly, and Tanya required that students go out into the community, Michael and Gavin's approaches did not necessarily require students to leave campus or enter unfamiliar places but rather imagine parts of the predominantly white university campus as Black literacy spaces. These two instructors adopted an approach to community-based instruction that relied, to varying degrees, on students' own relationships and points of contact to gather interviews from Black community members.

Michael and Gavin's approach to community-engaged instruction depended, primarily, on students having shared interests or existing connections with Black communities in the Columbus area. It is worth noting that both instructors taught the course on campus after it was moved from the CEC. Michael was asked to teach the course on fairly short notice, and therefore, he had a limited amount of time to do the kind of pre-course community brokering that other instructors could do. Both Michael and Gavin, like Tanya and Jason, had previously been involved in Emily or Beverly's sections of LNBC as graduate students. Also, as mentioned earlier, Michael and Gavin, like Jason and Thomas, are white, male-identified instructors, but, unlike Jason, they did not have long-established connections to Black Columbus communities. These factors contributed to their bottom-up approach to the course, in which students became the primary brokers for community members. Instead of facilitating interviews for students or consistently bringing in community liaisons to help cultivate community-based relationships, Michael and Gavin placed greater responsibility on students to negotiate whom they would interview and where those interviews would take place.

Michael's version of the LNBC course asked students to reflect on their own personal interests and social connections before reaching out to community members for interviews. This, of course, was different from the ways previous instructors built the course around specific themes and particular Black communities. This decision led to students gathering interviews from a diverse range of Black communities and spaces around Columbus. Michael explains how his diverse class of students chose the community members whom they interviewed:

I had two Black military veterans in my class, and they expressed interest in working with Black veterans in the Columbus area. I had students who had connections to St. Stephen's Community House. And so those students decided that they wanted to work with Black staff members at St. Stephen's Community House and interview them about their literacy practices. I had STEM students who wanted to have conversations with Black STEM students here at Ohio State about their literacy practices. And then the final group was made up of a couple of artists who expressed interest in working with visual artists in the Columbus area ... Black visual artists in the Columbus area.

Michael hoped that by interacting with members of a wide range of Black communities, the students would develop a deeper appreciation of the "plurality of Black voices with different perspectives on the world, different perspectives on American society, and different perspectives on literacy." Michael privileged the students' interests and points of contact, whether those contacts were physically located on or off campus, in Black neighborhoods or not. As he suggests, most of the students did "go out into the community," based on their own connections and interests. In this way, Michael's approach does not appear all that different from previous approaches we've discussed. 
However, he did not occupy the role of community broker, nor did he rely on community liaisons to make connections for students. Most student groups formed based on their performance of the role of community broker for themselves. With Michael privileging student interests and contacts, he also imagined his classroom as a space where the students' intersectional identities-as Black military veterans or artists, for example-expanded the classroom out to the community.

While students taking on the role of community brokers proved valuable for most, Michael suggests some students had an easier time taking on the roles of community brokers for this educational experience than others. He contrasts the experiences of the Black veterans in his course who interviewed Black military veterans in the community with the STEM group who, while racially and ethnically diverse, had no Black students. According to Michael, "The conversations that the Black military veterans were able to record of other Black military veterans, they seemed much richer. There were more details there. Whereas the interactions that took place ... with Black STEM students felt a little bit more forced." He attributes this difference in interview quality to the students' own community member status. Michael explains that for the STEM group, "interviewing the Black students, the environment just wasn't as organic. It's like 'we're being forced to interview people in this community' rather than 'we are a part of this community." It is ironic that shared disciplinary backgrounds did not create a strong enough bridge between the STEM interviewers and STEM interviewees. The points of difference between the experiences of the STEM students and the Black veterans demonstrates how racial identity and experiences enable certain students to become community and cultural brokers more easily. Michael sees these "points of difference" as opportunities for connection.

Gavin similarly relied on students making connections between their own interests and the community members they interviewed. Like most of the other LNBC instructors, Gavin identified a Black community group from whom students would collect narratives. His section of the course "specifically worked with Black LGBTQIA communities of Columbus," thus focusing on sexual identities rather than occupation or professional trade (dancer, barber, minister, etc.) and was approved as an ad hoc elective for the Women's, Gender, and Sexuality Studies program. Following Eric Darnell Pritchard, Gavin aimed to teach students how to recognize phenomena like "literacy normativity" (28) as well as "restorative literacies" (33) in the narratives of Black LGBTQIA Columbus communities. ${ }^{4}$ And while the course afforded Gavin the opportunity to teach content in his research specialization of "Black and Queer rhetorics and literacies," he "let [students] define themes that they want to ask about." In other words, Gavin offered broad parameters for qualifying community participants, but students themselves determined their research topics and questions following specific instruction in Black LGBTQIA histories as well as qualitative research methods. Students, then, pursued a wide range of topics related to Black LGBTQIA literacy, including "social media and Black LGBTQIA identity," "coming out stories as literacy events," and "the intersections between race, sexuality, and spirituality."

Like Michael, Gavin did not require students to "go out into the community" off campus to collect narratives. Yet, while most of the students in Michael's class ventured off campus, students in Gavin's class mostly stayed within Ohio State boundaries, seeking out Black community spaces within 
campus. Gavin was not intimately familiar with the Black LGBTQIA community in Columbus. His most sustained interactions with the community came from his earlier experiences as graduate student and technology assistant in Emily's and Beverly's sections, respectively. His limited knowledge closed off some paths (Approaches 1 and 2, for example) but opened up another path for Gavin and the students to engage Black LGBTQIA students and learn about the development of Black LGBTQIA student communities in a predominantly white space (the Ohio State campus). While Gavin did not emphasize moving into Black geographical neighborhoods or community places, he built on his existing networks and invited a panel of Black LGBTQIA community activists-whom Gavin had previously interviewed as part of Emily's LNBC course-into dialogue with his class. He also assigned readings and videos that provided cultural context for students and required attendance to a talk on Black LGBTQIA literacies by Eric Darnell Pritchard happening on Ohio State's campus. In that sense, he brought "the community" into his classroom and provided important cultural background for the class and the students' projects. We can look at Gavin's use of the panel as an act of community brokering-connecting students with community members-wherein the activists themselves functioned as cultural brokers who could provide cultural and community insights that synthesized course readings, viewings, and lectures with the local community's experiences.

Because Gavin imagined his LNBC class as situated on the Ohio State main campus, he made the racialized spaces of the university prominent in his thinking about his LNBC course:

[W] 're at a predominately white institution, and I don't think many of our students, especially our white students, take the time to consider subjectivity outside of their own. And, so what this course provides is that opportunity to really dig deep and understand, or at least attempt to understand or attempt to listen to the ways the people have to navigate their daily lives through certain practices certain literacy practices that are probably quite different than their own.

Gavin notes that none of the students belonged to Black LGBTQIA communities but that this outsider status may have positively contributed to their educational experiences. The teacher was not positioned as a community broker; instead, students took on the role of community broker by finding and building connections through their on-campus and local networks, which mostly occupied geographical and physical places on or around Ohio State campus such as the student union, library, classrooms, dorms, and neighborhoods. Having students act as community brokers encouraged them to be "more perceptive and better listeners" to people who have different cultural backgrounds and life experiences. Given the independence the students had, the networks that grew out of students' connections centered individuals who were on campus and "in that college age-18 to 24ish." Gavin's positionality and experiences as a white, cis-gay man new to Columbus obviously impacted his ability to imagine the places and spaces of this course. Unlike Approaches 1 and 2, Approach 3 did not define Black Columbus as a place necessarily beyond the university campus. Nonetheless, as Gavin explains, a group of mostly white cis-heterosexual students learned about Black LGBTQIA literacies from Black LGBTQIA people in the university community. This "learning from," again, highlights the importance of understanding communities as experts, not simply research subjects, as well as demonstrating how our understanding of certain physical places 
as white and cis-heterosexual can be transformed into Black LGBTQIA spaces through community literacy work.

Michael and Gavin's interviews illustrate several successes and challenges that come with instructors relinquishing the role of community broker. Students admirably stepped up when asked to find and record interviews, though some students had an easier time than others accessing Black community spaces to complete the coursework. The communities these students engaged were ones in their immediate vicinity and comfort level. But this comfort with these places does not negate the important work of investigating difference through literacy and race. In fact, we argue, this kind of comfort, just like the discomfort emphasized in interviews reflecting the "going out" approach, can complicate the ideas LNBC aims to address; that is, this work also reinforces Kinloch's troubling of suspicious distinctions. Students, for example, can understand the overlapping nature of raced spaces: entering a Black student's dorm room—a Black place-that simultaneously exists within the predominantly white space of Ohio State's campus. Given Michael and Gavin's own positionalities, their imagining of the classroom and community spaces dictated how students established a framework for negotiating movements across boundaries.

Michael's approach, encouraging students to imagine their shared identities and interests with community members, made a point to question the ways certain shared identities are complicated by racial and spatial difference. Take, for example, the group of STEM students interviewing Black STEM students. Michael's note that these interactions seemed forced and inorganic reveal something crucial about the ways we imagine shared values and experiences within certain academic disciplines. Whether these interviews with community members become rote work or develop into dynamic interactions may depend on students finding common touchpoints in their engagement with others and valuing differences in the experiences of others. This approach suggests that the bonds that lead to successful community brokering extends beyond vocation. LNBC offers interviewers the possibility to understand how race and space can inflect one's experience within a field.

Like Michael, Gavin's use of the "student networks" approach did not produce the kind of reciprocity that other approaches facilitate. For Gavin, a strong emphasis was placed on learning about Black LGBTQIA communities before learning with them. Because of the particularly sensitive nature of talking with community members about the intersections of race, sexuality, and literacy, Gavin concerned himself with offering students not only a deep context in the histories and languages of Black LGBTQIA literacies but a vocabulary for addressing these "taboo" topics with fellow students. Course texts and assignments, then, addressed issues like chosen family and queer kinship, queer spirituality, Black LGBTQIA representation in media, and local histories before students approached community members to request interviews. By leaning into the networks students could readily broker themselves, Approach 3 allowed for this kind of introduction to the specific languages and literacies of Black LGBTQIA communities while also leaving space for students to pursue issues relevant to the individuals sharing their literacy experiences. Approach 3, unlike Approach 1 and 2, places an increased burden on students to develop their networks to find community members willing to participate in the interview process. When the students have these existing connections, Approach 3 offers an opportunity for students to bring personal interests, friends, and family 
members into their learning experiences. When students do not have these connections, the interview gathering process can become much more challenging and unnatural. However, this approach helps instructors, students, and community members reimagine the university as a space that encapsulates the diversity of the Black experience through discussions of literacy as well as looks toward future action made more possible through the sharing of stories.

\section{CONCLUSION}

Through the LNBC course, we see how the positionalities of instructors influenced the degree to which they imagined and negotiated the roles of community and cultural brokers who facilitate, for students, access to community members and their cultural knowledge. Examining how instructors designed, implemented, and reflected upon the LNBC course prompted our reflection on the ways that this particular course asked instructors (and later students) to both define and negotiate boundaries between university and community, particularly in considerations of race, space, and place. While we don't make a value judgment about whether one approach was more effective than the other-especially given other contributing factors like instructor rank, course location, and material resources-we acknowledge that each approach sets up a different relationship among instructors, students, and community participants; offers different opportunities for brokering; and gives rise to different challenges when considering reciprocity.

The first approach, being embedded in the community, relied on the physical location of the course in a Black community space. This approach provided students opportunities to see literacy as it is practiced in community spaces. Even more important, it included community members who participated as community brokers-facilitating student access to other community spaces and setting up meetings with community members - and as cultural brokers, providing insider knowledge. Emily and Thomas, the two white senior faculty who designed the course, relied heavily on a key Black community member, Paulette, and her role as both community and cultural broker, to help them gain entrance into community places where they saw a value in embedding the course. This approach focused more on the literacies that function within Black Columbus spaces and specific places while not centralizing the relationship to the University. In Approach 1, embedded community liaisons were situated as co-teachers who had a sustained expert role in a class situated in their home communities. Community liaisons developed relationships with instructors and students and connected them to the liaisons' communities. Liaisons (and other community participants) also took the opportunity to use and learn about the digital tools and resources available in the LNBC course to suit their needs. Thus, this approach offered an opportunity for reciprocity while centering the expertise of community liaisons and relying on community liaisons to act as both community and cultural brokers.

The second approach, going out into the community, still emphasized the importance of being in community spaces, but the boundaries between the predominantly white university spaces and Black community spaces were more defined and emphasized. Whereas the first approach featured Paulette and other community members as community and cultural brokers, this approach required 
that instructors do community and cultural brokering work. In this second approach, instructors' positions in and ties to local Black communities proved major assets for how the instructors imagined and situated their versions of LNBC. By connecting students with Black communities and requiring them to visit particular places, these instructors-Beverly, Jason, and Tanya-built on their community and insider knowledge and connections to broker university-community boundaries. Approach 2 emphasized the differences between Ohio State as a predominantly white racialized space and place and those Black community spaces and places in which students collected literacy narratives. This approach, much like Approach 1, highlights crossing distinct boundaries-linking literacy practices with the practices within physical locations-for example, Black hair and nail salons, Black churches, and the CEC itself.

Finally, the third approach, relying on student networks, positioned students as community brokers. As in the other approaches, instructors did some brokering work by inviting community members to class, assigning relevant readings, and facilitating discussion to help students consider literacy as a concept inflected by race and space. Unlike other approaches, this approach relied much more on students' points of contact with Black communities, influencing the spaces and places of the course and the ways that Black communities were conceptualized. "Community" became less tied to geographical neighborhoods than in the first two approaches. The boundaries between predominantly white university spaces and Black community spaces were much less emphasized than in Approach 2. In Approach 3, although students might not have felt the discomfort of crossing into unfamiliar places, they confronted how the community members they interviewed might experience and navigate even familiar spaces differently. The third approach, used primarily by two white, male instructors, points to how instructors imagine the spaces and places of LNBC when they have fewer connections to Black communities.

The three approaches that emerged from our interviews show us, yet again, just how important understanding race, space, and place is when designing community-engaged courses and brokering relationships between students and communities. More specifically, our analysis prompts further reflection on the influence instructors' race and positionality has when developing such a course. For example, the second approach depended very much on the deep roots and connections that the instructors had within Black communities. These deep roots and connections, for the most part, are also tied to the race of the instructors. Of the three instructors who were most embedded in local Black Columbus communities, two-Beverly and Tanya-are Black women who had either lived in Black communities or were embedded in strong Black networks. The third, Jason, as we highlighted earlier, is a white male poet who had sought out and established deep connections to the Columbus Black poetry community before having the opportunity to teach LNBC. These were the instructors who took on the role of both community and cultural brokers. Clearly, LNBC is not dependent on being taught by Black instructors. Of the instructors who've taught the course, only three are Black. For instructors like Gavin and Michael, white instructors who had few ties to Columbus's Black communities, it was important to support student brokering through course readings, guest speakers, discussion, and assignments, and to be flexible and in constant communication with students who were doing their own community brokering. Our analysis of these three approaches 
suggests that the instructor's race, as well as the instructor's situatedness in racialized spaces and places, plays an important role in how LNBC is designed and executed.

As we discuss above with each approach, determining whether LNBC, in its design and execution, benefitted community participants is complicated. Our analysis shows that the physical location of the course, the role of community participants, and the depth of connections between instructor and Black Columbus communities seemed to contribute to how strong and visible the reciprocal relationships were. While some reciprocal relationships were built around specific community participant requests, other reciprocal relationships focused on broader (and sometimes vague) community values as defined by academic goals, such as the value of archiving some of the narratives in an instructor-designed open access, digital archive of literacy narratives or the digitallycurated student projects. Community partners did not request the archive nor the student projects though many were delighted with the students' video presentations. Clearly, then, one of the major questions to arise out of this project is how to make LNBC more responsive to community participant needs.

The approaches that arose from our analysis illustrate how instructors grapple with challenges and respond to opportunities created by the racialized and spatialized boundaries of communityengaged writing courses. Moreover, our analysis demonstrates how important identity and positionality are in enabling instructors to imagine and navigate the complexities of race, space, and place in their courses. Institutional "By unpacking the relationship between status, community relationships, instructor positionalities and course approaches, creative interests, and other identity we encourage other instructors to reflect on characteristics all influence how the contexts in which they themselves offer instructors imagined and taught community-engaged writing courses, particularly LNBC. By unpacking the relationship at PWIs." between instructor positionalities and course approaches, we encourage other instructors to reflect on the contexts in which they themselves offer community-engaged writing courses, particularly at PWIs. Further, extending Alvarez's concept of "brokering" to consider the creation of university-community connections (community brokering) and sharing of cultural knowledge (cultural brokering) within and across racialized spaces provides a useful conceptual framework for instructors of these courses. Rather than presenting our approaches as models for community-engaged teaching, we suggest that instructors consider how their identities and positionalities allow them to facilitate educational community interactions inflected by race, space, and place. 


\section{NOTES}

${ }^{1}$ We recognize an important difference between "service learning" and "community-engaged" as descriptors (Morton; Deans). We use "community engaged" in this article because students don't necessarily provide a direct service to community partners in this course. Rather, students and instructors engage with community members through projects more akin to community-engaged research and oral history projects.

2 The area was referred to as Bronzeville as early as 1938 and renamed the King-Lincoln District in 2001 as part of a community restoration initiative. The latter names reference the presence of the Martin Luther King, Jr. King Arts Complex and the restored Lincoln Theatre, both within walking distance of the Community Extension Center. It is also often referred to as the Mount Vernon area.

${ }^{3}$ Emily and Thomas have retired, and all interviewees who were graduate students at the time of the interviews have completed their degree programs. After data collection was completed, two more graduate students, a white man and an African-American woman, taught the course in 2019 and 2020 respectively, and a Latino postdoc taught the course in 2021.

${ }^{4}$ Pritchard defines literacy normativity as "the use of literacy to create and impose normative standards and beliefs onto people whom are labeled alien or other" (28). An example of literacy normativity might include "targeting people for violence if they read LGBTQ-themed books. To counter literacy normativity, Pritchard calls for "restorative literacies," or "the application of literacies for self- and communal love manifested in a myriad of ways and across a number of sites and contexts toward the ends of making a life on one's own terms" (33). 
Brokering Comunity-Engaged Writing Pedagogies

\section{Acknowledgements}

We would like to thank Michelle Cohen, Jonathan Buehl, and the LiCS reviewers whose feedback helped improve this article. 


\section{WORKS CITED}

Albright, Thomas, Judson L. Jefferies, and N. Michael Goecke. "A Ruckus on High Street: The Birth of Black Studies at the Ohio State University." The Journal of Race \& Policy, vol. 9, no. 1, 2013, pp. 23-46.

Alvarez, Steven. Brokering Tareas: Mexican Immigrant Families Translanguaging Homework Literacies. SUNY P, 2017.

Blancato, Michael, Gavin P. Johnson, Beverly J. Moss, and Sara Wilder. "The Work of BoundaryCrossing in Community Engaged Literacy Work.” Journal of College Literacy and Learning, vol. 45, 2019, pp. 95-97.

Davi, Angelique, Michelle Dunlap, and Ann Green. "Exploring Difference in the Service-Learning Classroom: Three Teachers Write about Anger, Sexuality, and Social Justice.” Reflections: A Journal on Community-Engaged Writing and Rhetoric, vol. 6, no. 1, 2007, pp. 41-66.

Deans, Thomas. Writing Partnerships: Service-Learning in Composition. National Council of Teachers of English, 2000.

Druschke, Caroline Gottschalk, Megan Marie Bolinder, Nadya Pittendrigh, and Candice Rai. "Designing the Future: Assessing Long-Term Impact of Service-Learning on Graduate Instructors." Reflections: A Journal on Community-Engaged Writing and Rhetoric, vol. 14, no. 2, 2015, pp. 23-50.

Dunlap, Michelle, Jennifer Scoggin, Patrick Green, and Angelique Davi. “White Students' Experiences of Privilege and Socioeconomic Disparities: Toward a Theoretical Model.” Michigan Journal of Community Service Learning, vol. 13, no. 2, 2007, pp. 19-30.

Espino, Michelle M., and Jenny J. Lee. "Understanding Resistance: Reflections on Race and Privilege through Service-Learning." Equity \& Excellence in Education, vol. 44, no. 2, 2011, pp. 136-

52. https://doi.org/10.1080/10665684.2011.558424

Green, Ann E. "Difficult Stories: Service-Learning, Race, Class, and Whiteness." College Composition and Communication, vol. 55, no. 2, 2003, pp. 276-301.

Holmes, Ashley J. Public Pedagogy in Composition Studies. National Council of Teachers of English, 2016.

Kinloch, Valerie. Harlem on Our Minds: Place, Race, and the Literacies of Urban Youth. Teachers College Press, 2015.

---. "Suspicious Spatial Distinctions: Literacy Research with Students Across School and Community Contexts." Written Communication, vol. 26, no. 2, 2009, pp.154-82. https://doi. org/10.1177/0741088309332899

Kynard, Carmen. "Literacy/Literacies Studies and the Still-Dominant White Center." Literacy in Composition Studies, vol. 1, no. 1, 2013, pp. 63-65. https://doi.org/10.21623/1.1.1.16

Leander, Kevin M., and Margaret Sheehy, editors. Spatializing Literacy Research and Practice. Peter Lang, 2004.

Leon, Kendall, Laurie A. Pinkert, and Kathryn Trauth Taylor. "Developing Accounts of Instructor Learning: Recognizing the Impacts of Service-Learning Pedagogies on Writing Teachers." 
Composition Studies, vol. 45, no. 1, 2017, pp. 39-58.

Lum, Belinda C., and Michelle M. Jacob. "University-Community Engagement, Axes of Difference \& Dismantling Race, Gender, and Class Oppression.” Race, Gender \& Class, vol. 19, no. 3/4, 2012, pp. 309-324.

McKittrick, Katherine. Demonic Grounds: Black Women and the Cartographies of Struggle. U of Minnesota P, 2006.

Morton, Keith. "The Irony of Service: Charity, Project, and Social Change in Service-Learning." Michigan Journal of Community Service Learning, vol. 2, 1995, pp. 19-32.

“Our Mission.” Department of African American Studies Community Extension Center, https://aaascec.osu.edu/about-us/our-mission.

Pritchard, Eric Darnell. Fashioning Lives: Black Queers and the Politics of Literacy. Southern Illinois UP, 2017.

Selfe, Cynthia L., and H. Lewis Ulman. "Black Narratives Matter: Pairing Service-Learning with Archival Research in the Literacy Narratives of Black Columbus Project." The Archive as Classroom: Pedagogical Approaches to the Digital Archive of Literacy Narratives, edited by Kathryn Comer, Michael Harker, and Ben McCorkle, Computers and Composition Digital Press/Utah State UP, 2019. Retrieved from https://ccdigitalpress.org/book/archive-asclassroom/archive1.html

Shah, Rachael W. Rewriting Partnerships: Community Perspectives on Community-Based Learning. UP of Colorado, 2020.

Sheehy, Margaret. "Between a Thick and a Thin Place: Changing Literacy Practices." Spatializing Literacy Research and Practice, edited by Kevin M. Leander and Margaret Sheehy, Peter Lang, 2004, pp. 91-114. 